\title{
Sea Level Variations at Different Coastal Areas of Zhejiang Province, China
}

\author{
Binbin Yan', Wangyuan Zhu², Liuzhu Wang ${ }^{3}$, M. V. Subrahmanyam ${ }^{3 *}$ \\ ${ }^{1}$ Zhoushan Natural Resources Surveying and Mapping Design Center, Zhoushan, China \\ ${ }^{2}$ Zhejiang Haida Marine Survey, Planning and Design Co. LTD., Zhoushan, China \\ ${ }^{3}$ School of Marine Science and Technology, Zhejiang Ocean University, Zhoushan, China \\ Email: *mvsm.au@gmail.com
}

How to cite this paper: Yan, B.B., Zhu, W.Y., Wang, L.Z. and Subrahmanyam, M. V. (2021) Sea Level Variations at Different Coastal Areas of Zhejiang Province, China. Open Access Library Journal, 8: e7539. https://doi.org/10.4236/oalib.1107539

Received: May 18, 2021

Accepted: June 6, 2021

Published: June 9, 2021

Copyright $\odot 2021$ by author(s) and Open Access Library Inc.

This work is licensed under the Creative Commons Attribution International License (CC BY 4.0).

http://creativecommons.org/licenses/by/4.0/

\section{(c) (i) Open Access}

\begin{abstract}
In this paper we consider the different locations of Zhejiang (ZJ) provincial area including Hangzhou Bay (HZB), Ningbo (NB), Zhoushan (ZS), Taizhou (TZ) and Wenzhou (WZ) subareas to find out the sea level (SL) variations. Sea Surface Height Relative to Geoid over these areas has been obtained from the satellite altimetry data produced routinely by the European Centre for Medium-Range Weather Forecasting (ECMWF) and Archiving, Validation and Interpretation of Satellite Oceanographic (AVISO) data. Monthly, seasonal and interannual variations of SL over ZJ provincial areas have been presented and discussed. SL is indicating an increasing trend, however there is a decreasing trend between the years 1975 and 1987, in later years SL increasing. Over Zhejiang provincial areas revealing increasing trend in SL. Negative relation between SL and Sea surface temperature (SST) found over ZJ province areas.
\end{abstract}

\section{Subject Areas}

Environmental Sciences, Geomorphology, Natural Geography

\section{Keywords}

Sea Level, Zhejiang Province, Satellite Altimetry Data, SST

\section{Introduction}

Earth's response to climate change can be observed from the Sea level (SL) variation, which is one of the important parameters [1]. SL rising is receiving more attention for global researchers as one of the catastrophic consequences of climate change. SL rise is a matter of urgent concern, especially because many 
low-lying parts of the world undergoes consequent threats [2] [3] [4] [5]. Since 1980 , an increasing trend in SL observed Globally. However, SL rise over China's coastal sea level is higher than that of the world [6] [7]. Since 2000, China's coastal SL continued to be increasing and 2012 reached its highest level since 1980, however 2005 year shows decline [8]. From 2010 to 2012 China's coastal SL have high periodical oscillation, several high superimposed periodical oscillations had obvious effect on the sea level. In 2012, coastal temperature and SST were higher $0.4^{\circ} \mathrm{C}$. The anomaly of the wind leads to water accumulation is one of the causes of rising sea levels. In 2012, it was the tropical cyclones landing time and had broad influence, especially in August 2012 has six tropical cyclones affected China's coastal area and had made obvious effect on sea level rise in that month. Subtropical high in 2012, northerly wind has influence in rising in SL over the east China sea and south China [9]. In the context of global warming, sea level rise has become a major global environmental problem. Impact of rising SL on the economic development of coastal areas, marine ecological environment and people's production and life is increasingly significant.

Global sea level rise is caused by climate warming, swelling of the sea, continental glaciers and melting of polar ice caps. Under the background of global climate change, China's coastal have higher temperatures and SST and lower pressure, then leading to increase in sea level. SL rise will lead to threat in the coastal cities flood control and water supply system. The change of offshore SL is related to the human living environment and its development prospects, so SL gets more attentions. In recent decades, many experts have made lot of investigations to get consistent understanding. In recent 100 years, the global sea level is on the rise and the average rise rate is about $1.0-2.0 \mathrm{~mm} / \mathrm{a}$ according to previous studies [10]-[17]. Average annual variability of the sea level along the coast of China is in the same range however, there are significant differences in SL in different regions.

Mean global SL and mean global sea surface temperature (SST) has strong correlation [18], which suggests that the steric effect impact sea level signature. In addition to global warming factors, in the long-term scale, SL changes are affected by structural changes in the earth, the activities of the great glacial period and the effects of the atmosphere, the ocean itself, etc. Numerous studies have shown that the change in SL is closely related to the water thermal expansion [9]. [19] [20] [21] [22] [23]. Further this is supported by the strong similarity of the spatial distribution of satellite-observed in sea level variations and surface temperature [24] [25] [26]. By 2100 rise in temperatures is predicted by $2^{\circ} \mathrm{C}-4.4^{\circ} \mathrm{C}$ leading to global average sea level rise of 2 - $6 \mathrm{~mm}$ per year up to 2100 [27] which impacts the protected coastal habitats. Local SST variations of about $0.58^{\circ} \mathrm{C} / \mathrm{yr}$ observed and would be adequate for sea level rise. Temperature to sea level relationship may differ from the surface temperature to sea level relationship on this long timescale, which is caused by the ocean circulation [28] [29] [30] [31]. In this paper we find out the relation between the SL and SST over the 
Zhejiang province coastal areas.

\section{Study Area and Data}

Zhejiang is a province with the most islands in China. Zhejiang coastline extending 6486 kilometers and a total ocean area of 220,000 square kilometers. In addition, the province has a large number of bays with over 60 natural ports. Zhejiang is located in the southern part of the Yangtze River Delta on the southeast coast of China, which accounts for sediment transport to sea. The Study area we chosen $26^{\circ} \mathrm{N}-32^{\circ} \mathrm{N}: 119^{\circ} \mathrm{E}-124^{\circ} \mathrm{E}$, which in the East China. Further the coastal areas have been chosen to find out the variations of SL over Zhejiang Province given in the Figure 1 and they are as follows: (a) Hangzhou Bay (HZB) $30^{\circ} \mathrm{N}-31^{\circ} \mathrm{N} ; 120^{\circ} \mathrm{E}-122^{\circ} \mathrm{E}$, (b) Ningbo (NB) $28^{\circ} \mathrm{N}-31^{\circ} \mathrm{N} ; 120^{\circ} \mathrm{E}-123^{\circ} \mathrm{E}$, and (c) Wenzhou (WZ) $27^{\circ} \mathrm{N}-29^{\circ} \mathrm{N} ; 119^{\circ} \mathrm{E}-122^{\circ} \mathrm{E}$.

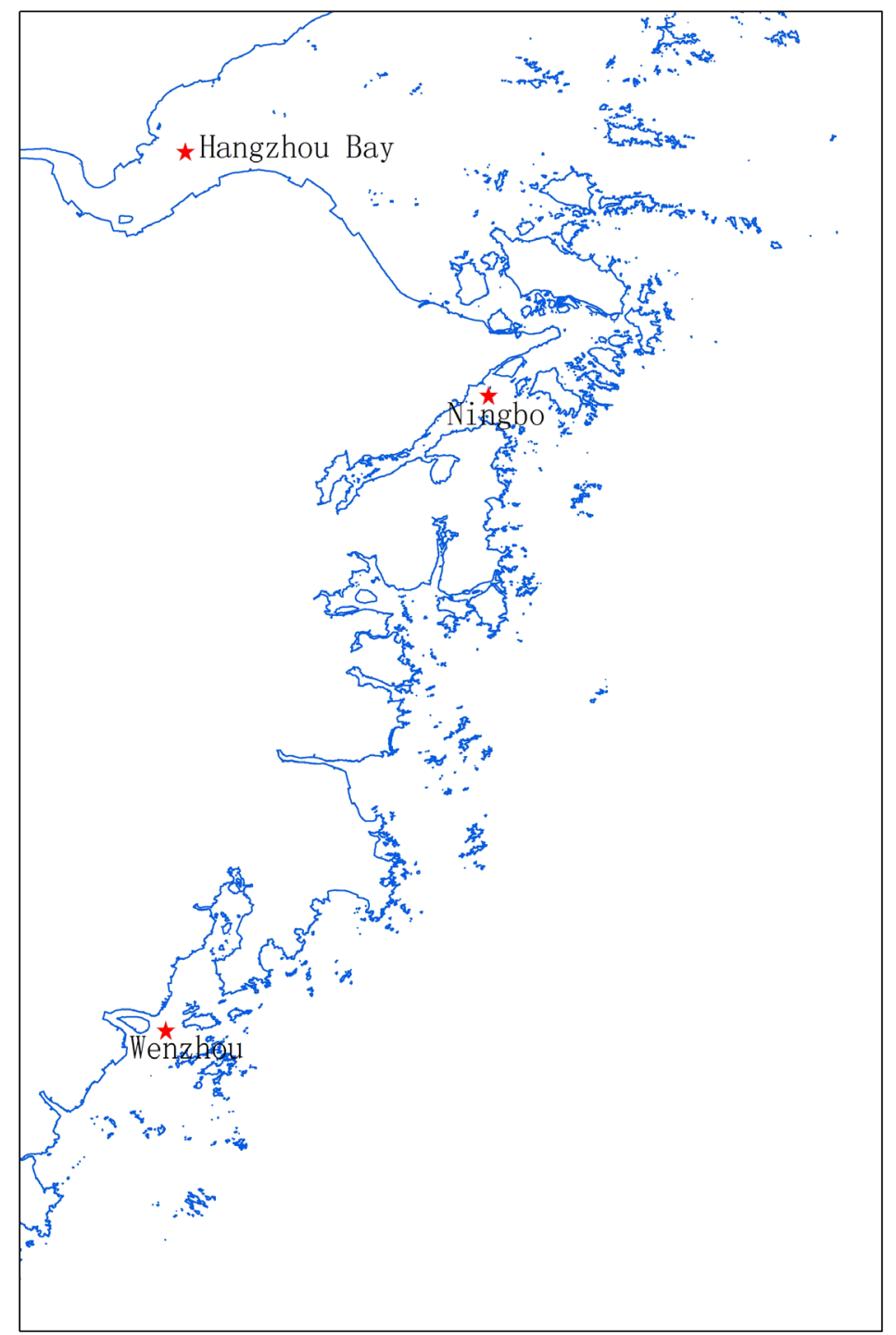

Figure 1. Study area which includes the coastal areas of Zhejiang province. 
Sea Surface Height Relative to Geoid over the area has been obtained from the operational ORAS4 data used for this analysis. The European Centre for Medium-Range Weather Forecasting (ECMWF) estimates the state of the global ocean via the operational system Ocean-S4. Ocean-S4 gives an estimate of the history of the ocean from September 1957 to present (with a few days delay) via the Ocean Reanalysis System 4 (ORAS4), as well as the latest ocean conditions, provided by the real-time extension Ocean Real Time Analysis System 4 (ORTA4). In this study, the data over the period of January 1958 to December 2015 monthly SL data used to find the variations in the study areas.

To validate the relation between the SL and SST relation we have used the dataset HadISST (Hadley Centre Global Sea Ice and Sea Surface Temperature) is a combination of monthly globally complete fields of SST and sea ice concentration for 1871-present. HadISST uses reduced space optimal interpolation applied to SSTs from the Marine Data Bank (mainly ship tracks) and ICOADS through 1981 and a blend of in-situ and adjusted satellite-derived SSTs for 1982-onwards. The "bucket correction" was applied to SSTs for 1871-1941. HadISST is primarily intended to be used as boundary conditions for atmospheric models. With above mentioned data sets SL variations computed and presented in following sections and given the relation between SL and SST.

\section{Results}

\subsection{Monthly Variations of SL}

Monthly SL variations over Zhejiang province areas are presented in the Figures $2(a)-(c)$. One can clearly observe that SL is showing an increasing trend over Zhejiang province areas (HZB, NB, WZ). SL is varying between $-0.26 \mathrm{~m}$ and $0.29 \mathrm{~m}$ over HZB, $-0.24 \mathrm{~m}$ and $0.28 \mathrm{~m}$ over $\mathrm{NB},-0.24 \mathrm{~m}$ and $0.29 \mathrm{~m}$ over WZ respectively. Lower SL monthly variations can be observed in 1961-62, 1967-68. Higher SL anomalies observed in 2013, however over HZB and NB 2014 also showing higher SL. Higher values of SL can be explained as the more rainfall leading to more river discharge and higher SST values over the study area. Monthly plot is revealing there is a seasonal variation, which are discussing in the next section.

\subsection{Seasonal Variations of SL at Different Seasons}

Figure 3 depicts the seasonal variation SL over the Zhejiang province areas. SL variations are indicating increasing trend in every season. Autumn season SL in higher and spring season is lower than the other seasons. Higher SL in autumn is due to higher rainfall, more river runoff, however it is found that higher typhoon activity observed in the summer especially in the August month [32]. From 1975 to 1987 seasonal SL is showing decreasing trend, then have an increasing trend.

Over the HZB (Figure 3(a)), the seasonal ranges in different seasons are given as follows: in the spring SL varies between -3.8 and $-19.1 \mathrm{~cm}$, in summer -5.09 and $20.8 \mathrm{~cm}$, in autumn $7.2-20.8 \mathrm{~cm}$ and in winter -16.7 and $3.1 \mathrm{~cm}$ respectively. 


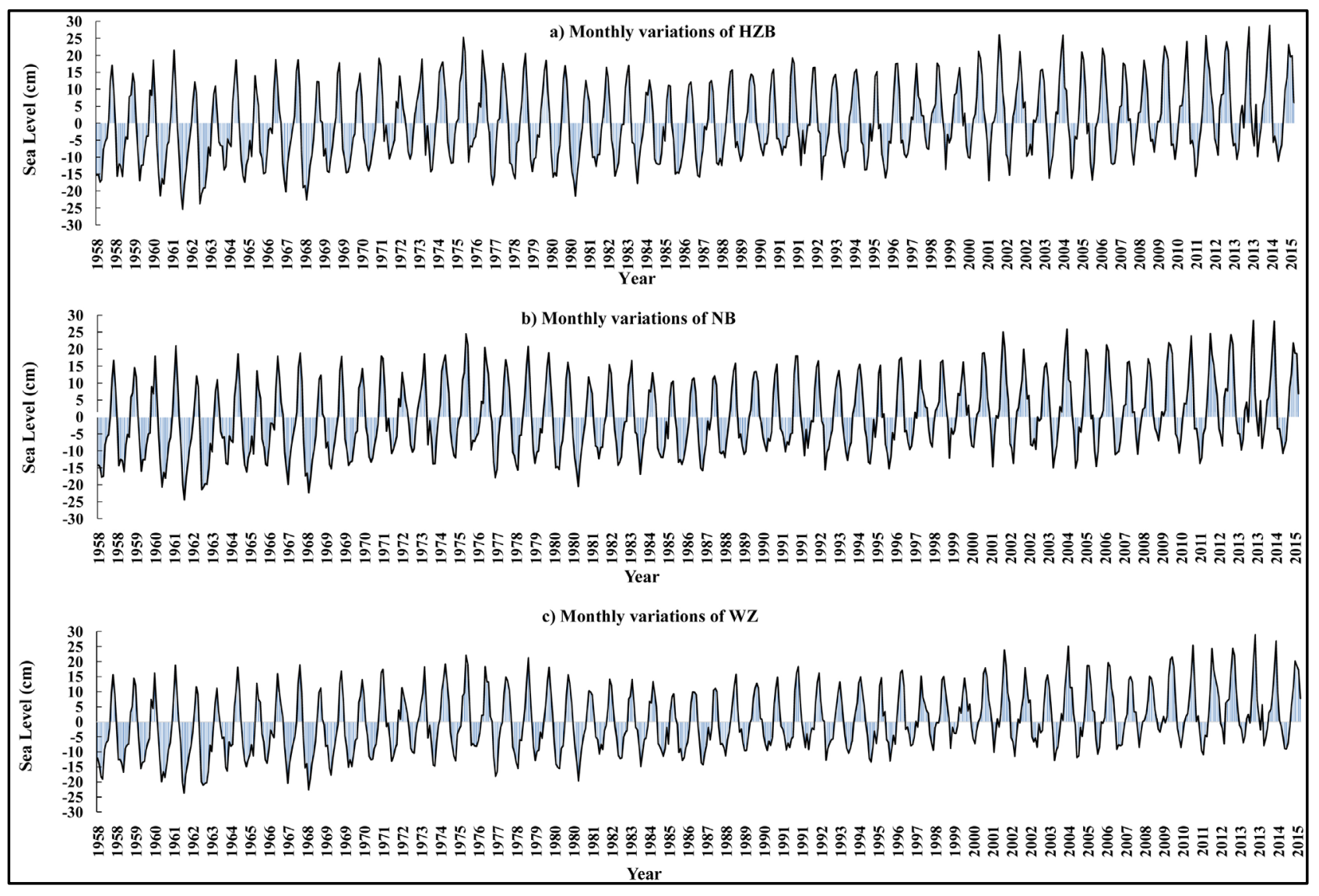

Figure 2. Monthly variation of Sea level anomalies over different areas of Zhejiang Province ((a) Hangzhou Bay (HZB), (b) Ningbo (NB) and (c) Wenzhou (WZ) for the period 1958-2015.

In NB (Figure 3(b)), spring SL varies between -2.7 and $-18.5 \mathrm{~cm}$, in summer -5.9 and $20.5 \mathrm{~cm}$, in autumn 6.96 and $20.54 \mathrm{~cm}$ and in winter -15.7 and $4.4 \mathrm{~cm}$ respectively. In WZ (Figure 3(c)), the seasonal ranges in in the spring SL varies between -0.7 and $-19.1 \mathrm{~cm}$, in summer -7.4 and $20.2 \mathrm{~cm}$, in autumn 6.3 and $20.2 \mathrm{~cm}$ and in winter -15.5 and $6.5 \mathrm{~cm}$ respectively. These ranges clearly indicating that SL of WZ higher that other two areas and is due to the impact of lower latitude as well the intrusion of Kuroshio current. The steric effect of the SST is higher in the lower latitudes.

\subsection{Annual Variations of SL}

The interannual SL variations of the Zhejiang provincial coastal areas (HZB, NB and WZ) are depicted in Figure 4 and showing an increasing trend. The SL in the WZ is higher than other two areas (NB and HZB). This variation is SL can be explained as the latitudinal effect. Previous studies concluded that large deflection of the Kuroshio can lead to the rise in SL [33]. Because during the great bend of the Kuroshio, it carries a large amount of high temperature and high salt water into the East China Sea, It has a great influence on the marine environment in the East China Sea [34] [35], Sea level change is the appearance of this effect. At the same time, we can also see some years of low sea level, for instance 


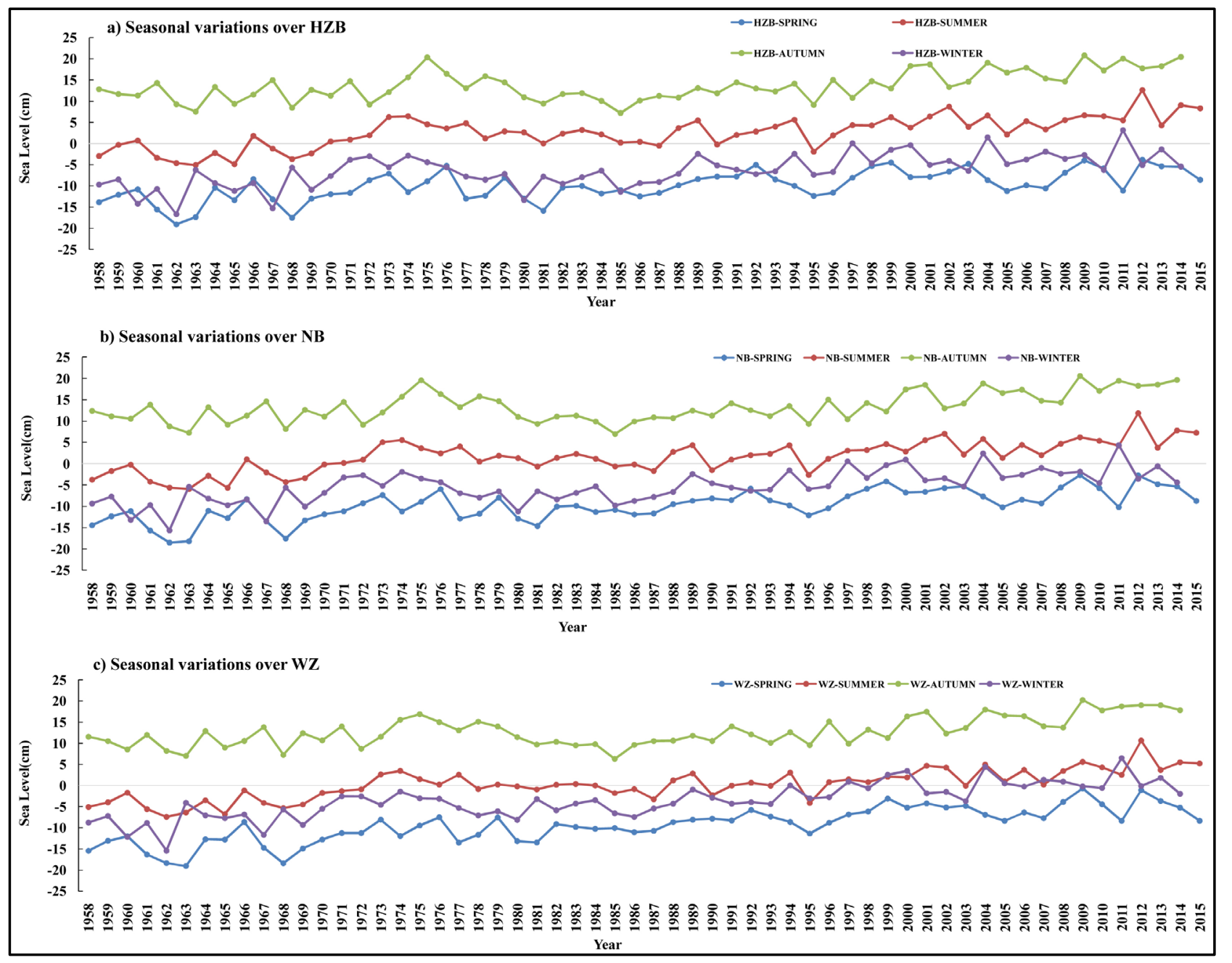

Figure 3. Seasonal variation of SL over different areas of Zhejiang Province ((a) Hangzhou Bay (HZB), (b) Ningbo (NB) and (c) Wenzhou (WZ)) for the period 1958-2015.

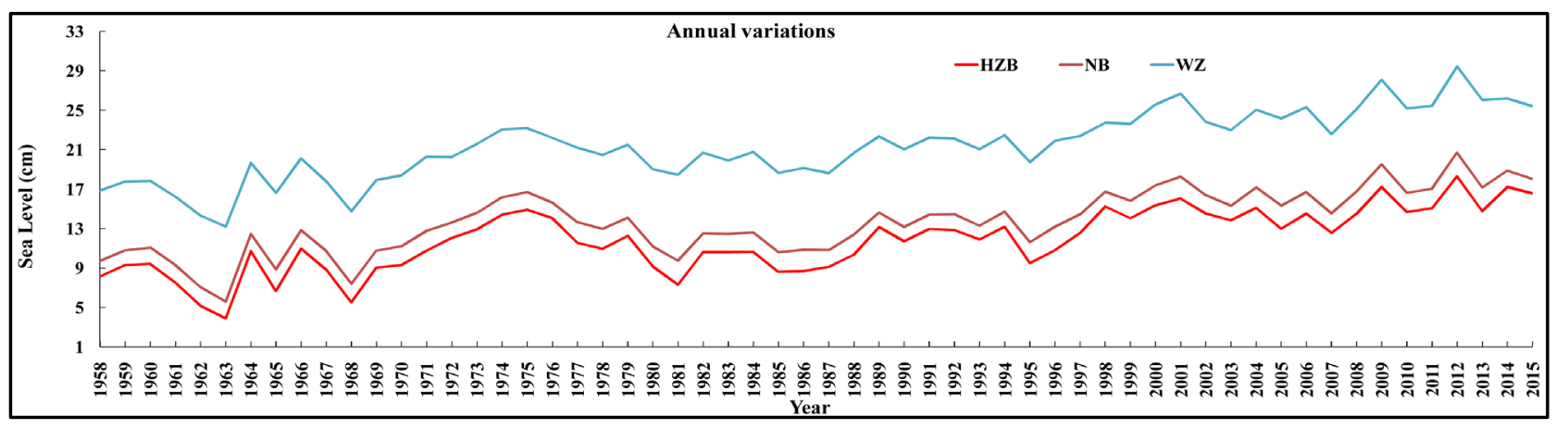

Figure 4. Annual variation of SL over different areas of Zhejiang Province ((a) Hangzhou Bay (HZB), (b) Ningbo (NB) and (c) Wenzhou (WZ)) for the period 1958-2015.

1963, 1968, 1981, 1985, 1988, 1995, 2002, 2007 and 2015. SL decreased in the study period in the El Nino, Lower SL clearly indicating that El Nino events have a great influence on Zhejiang provincial areas to modify SL. Western Pacific sea water cooling, so that the sea level dropped and the East Pacific Ocean warming, 
sea level rise during the formation and development of El Nino [36].

Figure 5 clearly indicates the increasing trend of SL over HZB, NB and WZ areas of Zhejiang province. In the study period, lower anomalies of SL observed till 1973, there is an increase in SL for in 1976, then decrease again and fluctuations in SL can be seen till 1995 and an increase trend till 2015. However, 2005 is special case which has lower SL. Year 2005 is a special ENSO events in recent decades, and have the distinctive evolution features compared to the typical ENSO events. The typical El Nino has a fast decaying after its peak [37]. Weak warm phase in the first half of 2005, mean SST anomalies were observed in the central equatorial Pacific Ocean are higher, which peaks in May. In the western equatorial Pacific remained slightly above or near-normal in the last few months of 2005, however recent monthly mean anomaly in December 2005 decreasing below the long-term average.

\subsection{Decadal Variations}

Decadal anomalies clearly illustrate an increasing trend of SL (Figure 6). The decade 1968-1977, SL increased however in 1978-1987-decade SL declined, after

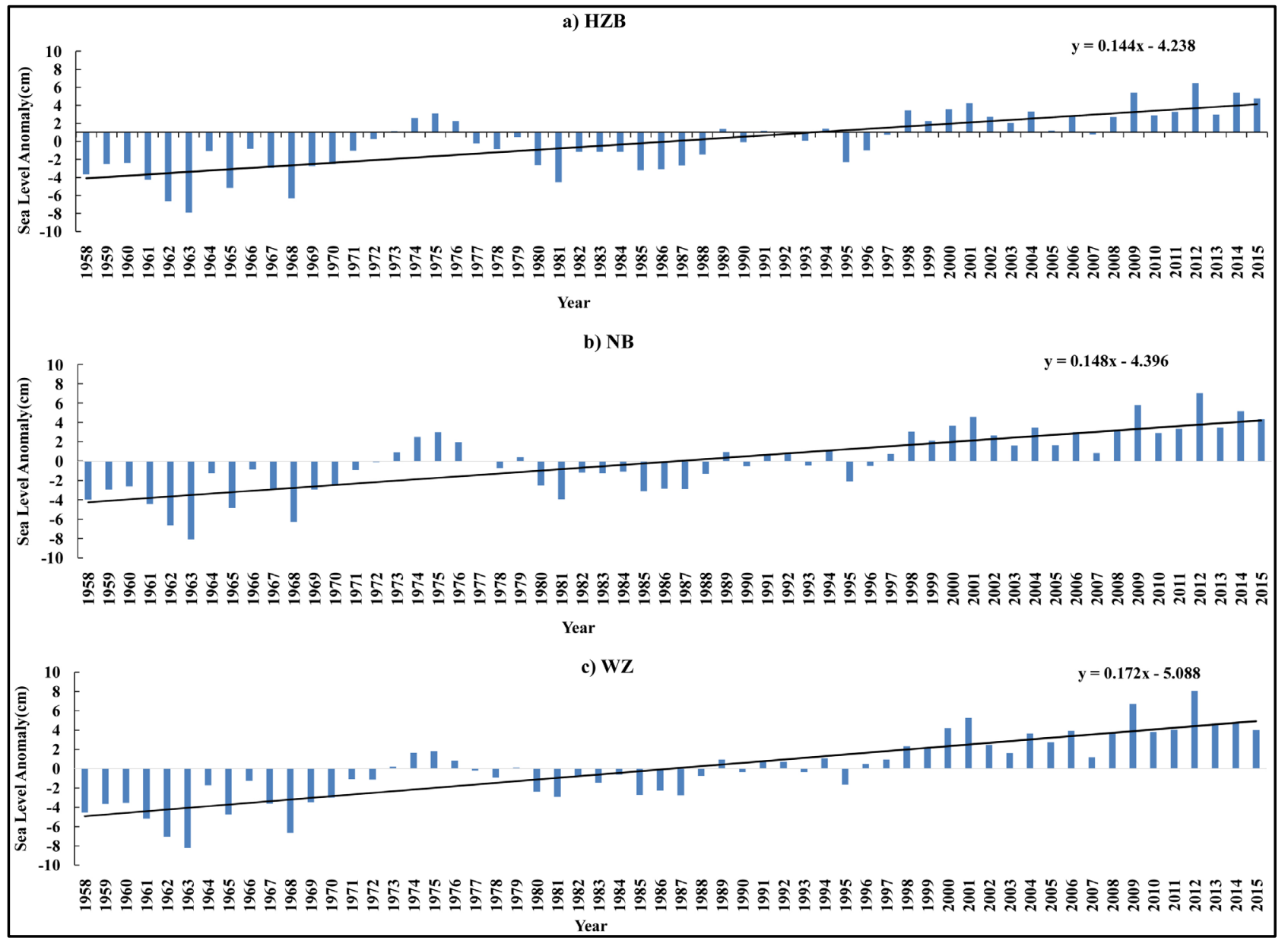

Figure 5. Annual SL anomaly variations over different areas of Zhejiang Province ((a) Hangzhou Bay (HZB), (b) Ningbo (NB) and (c) Wenzhou (WZ)) for the period 1958-2015. 


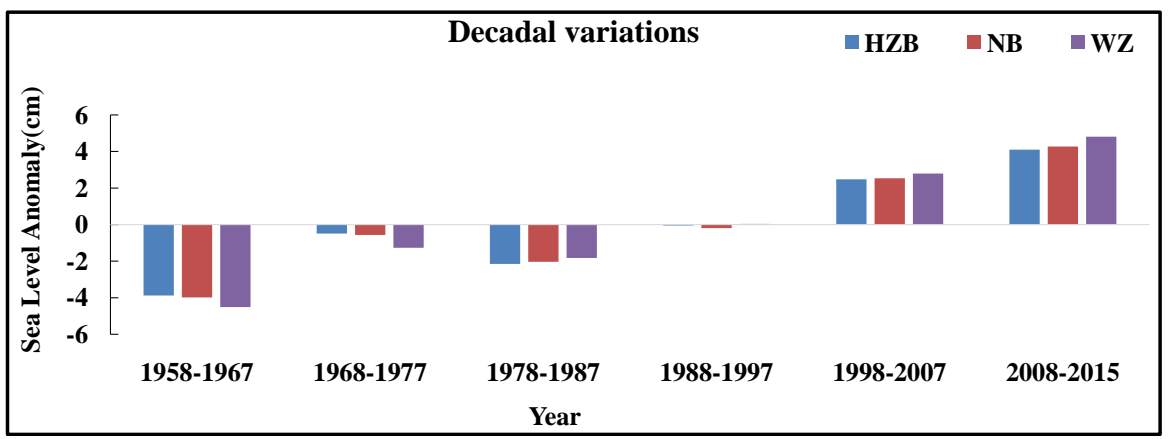

Figure 6. Decadal variation of SL over different areas of Zhejiang Province (((a) Hangzhou Bay (HZB), (b) Ningbo (NB) and (c) Wenzhou (WZ)).

that there is an increase trend in SL. Increase in SL after 1987 may be connect with the climate change, global warming and increase in temperature over the tropical Pacific Ocean.

\subsection{SL Variations Related to SST}

SST variations will inevitably lead to the change of sea level. This article uses the sea surface temperature (HadISST) data to find out the variations of sea surface temperature in Zhejiang province areas. We use HadISST (1958-2015) SST data and sea surface height data to find out the relation over the Zhejiang provincial areas and presented in Figure 7.

In order to further study the correlation between the SL and SST, we analyzed the correlation between SL and SST for the study period (1958-2015). The correlation coefficients are as follows: over the HZB the correlation coefficient (CC) between SL and SST is 0.72 , at NB the CC is 0.69 and at WZ the CC is 0.61 . The $\mathrm{CC}$ clearly indicating there is a significant relation between SL and SST. However, WZ is lower than HZB, this shows over the HZB region the influence of SST on SL is higher. The southern city of WZ having an influence of Kuroshio warm currents during the summer and in the winter, it was influenced by the cooler current coming from the northern side, also due to the rainfall and river runoff.

Global warming leads to expansion of the ocean, polar ice caps and terrigenous Melting glaciers are the main reason of global sea level rise [38]. From the global sea level rise distribution Sea level changes in the world oceans has obvious regional characteristics [27]. China's coastal areas are located in a relatively high level of sea level rise rate is higher [39]. Regional SL changes in addition to the affected by the global sea level change, also by the local SST, current, wind, temperature, pressure, precipitation and so on hydrologic meteorological elements [40], higher SST and lower pressure, sea level rise [8] [41]. Since 1990, with extreme weather and climate events occur frequently, resulting in the number of abnormal seasonal sea level increase obvious, anomaly values increased [42]. The affection of the East Asian monsoon changes also is the important cause of the change of China's coast and the neighboring seas Marine environmental elements, such as Seawater temperature and salinity, sea level, 

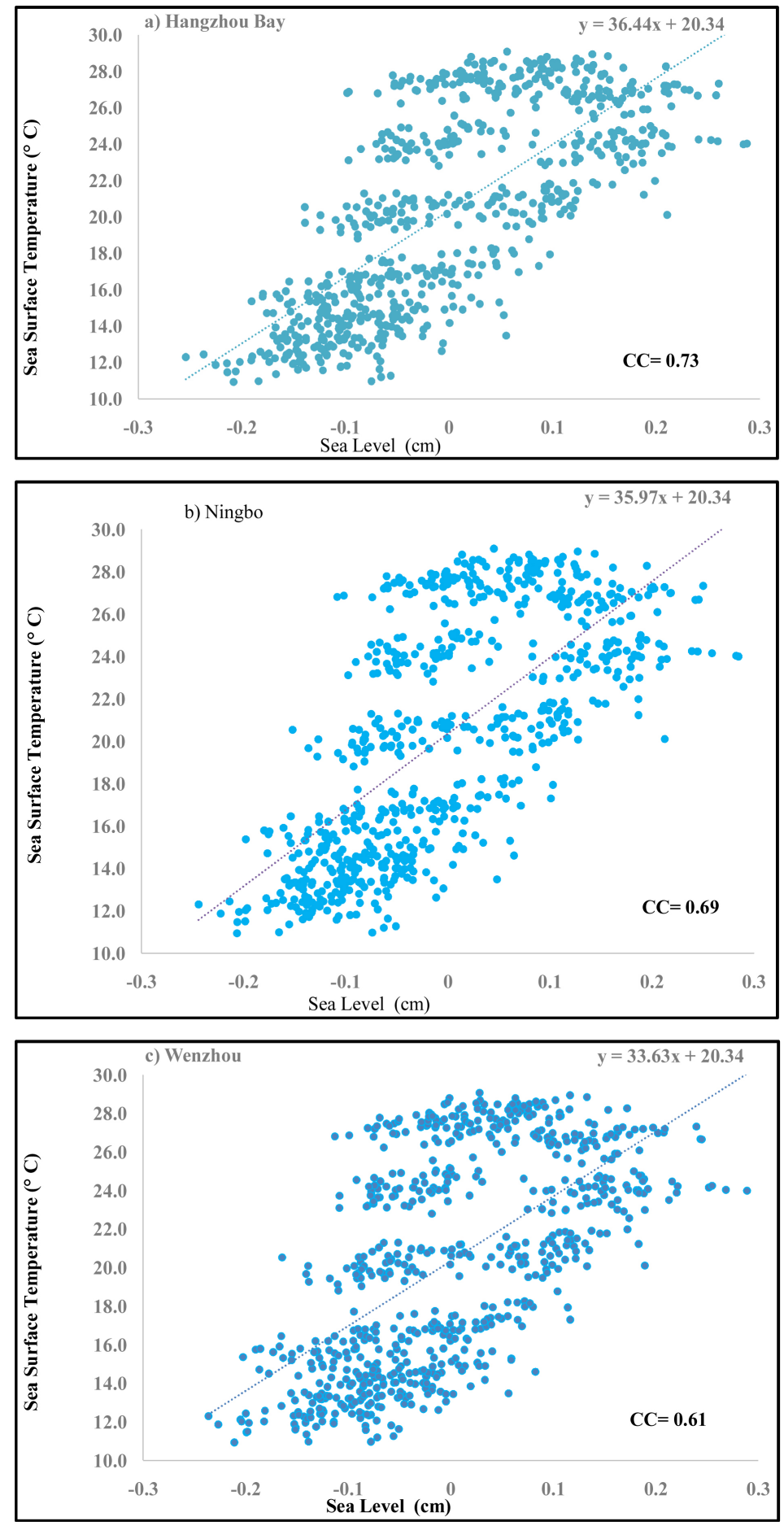

Figure 7. Relation between Sea level (SL) and Sea surface temperature (SST) during the study period (1958-2015) over Zhejiang province areas ((a) Hangzhou Bay (HZB), (b) Ningbo (NB) and (c) Wenzhou (WZ)).

etc [27] [43]. The relation between the sea temperature and SL is given in the Figures $7(a)-(c)$. There is a positive relation can be seen between SST and SL with the correlation of 0.7284 . And Figure 7 illustrating relation between SST and SL and indicating an increasing trend. 


\section{Conclusion}

Over the Zhejiang province areas SL is indicating and increasing trend from monthly, seasonal, annual and decadal variations. SL is increased $0.17 \mathrm{~cm}$ per year from 1958 to 2015. As previous studies indicating that SST is having an impact on SL, we found there is a positive relation between Zhejiang areas SST and SL. HZB area illustrating higher relation between SL and SST, however the seasonal annual plots showing latitudinal effect on the SL. WZ indicating higher SL than HZB. Local SST, river discharge, sediment in the water are having sufficient impact on the SL. However, Zhejiang provincial areas experience several typhoons, which may produce higher rainfall and changes in the sea surface heights, which may also have sufficient effect on SL.

\section{Acknowledgements}

Authors express their gratitude to ECMWF for providing sea surface height data freely and Hadley Centre Global Sea Ice and Sea Surface Temperature for providing SST data.

\section{Conflicts of Interest}

The authors declare no conflicts of interest regarding the publication of this paper.

\section{References}

[1] Nerem, R.S. and Leuliette, C. (2006) A Present-Day Sea-Level Change: A Review. Comptes Rendus Geoscience, 338, 1077-1083. https://doi.org/10.1016/j.crte.2006.09.001

[2] Douglas, B.C., Kearney, M.S. and Leatherman, S.R. (2001) Sea Level Rise: History and Consequences. Academic Press, Cambridge, 232 p. https://doi.org/10.1029/01EO00232

[3] Church, J.A. (2001) Sea Level Rise: History and Consequences. Eos Transactions American Geophysical Union, 82, 376-376.

[4] Church, J., Gregory, J.M., Huybrechts, P., Kuhn, M., Lambeck, K., Nhuan, M.T., Qin, D. and Woodworth, P.L. (2001) Changes in Sea Level. In: Houghton, J.T., et al., Eds., Climate Change 2001: The Scientific Basis, Cambridge University Press, Cambridge, 639-693.

[5] Woodworth, P., Gregory, J.M. and Nicholls, R.J. (2004) Long-Term Sea Level Changes and Their Impacts. In: Robinson, A.R. and Brink, K., Eds., The Sea, Biological-Physical Interactions in the Sea, Vol. 12, Harvard University Press, Cambridge, 717-752.

[6] Li, C.Y., Sun, S.Q. and Mu, M.Q. (2001) Origin of the TBO-Interaction between Anomalous East-Asian Winter Monsoon and ENSO Cycle. Advances in Atmospheric Sciences, 18, 555-566. https://doi.org/10.1007/s00376-001-0044-y

[7] Wang, H., Liu, K.X., Zhang, J.L., et al. (2013) The Sea Level Change of Sansha Seas. Acta Oceanologica Sinica, 35, 11-17. (In Chinese)

[8] The State Oceanic Administration (2013) In 2012 China Sea Level Communique.

[9] Ma, J., Zhou, Y.H., Liao, D.C., et al. (2007) Global Sea Level Change from 1992 to 
2007. Annals of Shanghai Astronomical Observatory, CAS, No. 1, 37-41.

[10] Zheng, W.Z. and Zhao, X.C. (1985) China's Coatime. Acta Oceanologica Sinica, 7, 276-279.

[11] Zheng, W.Z., Yu, J.Y. and Niu, B. (1992) Sea Level Research in China. Marine Science Bulletin, 11, 68-72.

[12] Chen, Z.Y., Huang, Y.H., Zhou, T.H., Tang, E.X., Yu, Y.F. and Tian, H. (1991) A Preliminary Study on Mean Sea Level of the Changjiang River Estuary. Oceanologia et Limnologia Sinica, 22, 315-320.

[13] Zhou, T.H. and Chen, Z.Y. (1992) China's Coastal Sea Level Change Trend of Research in Recent Decades. Acta Oceanologica Sinica, 14, 1-8.

[14] Yu, D.Y. (1986) Preliminary Analysis of China Coastal Sea Change Trend during the Past 20 Years. The Chinese Academy of Geological Sciences 562 Comprehensive Brigade Collected Papers.

[15] Fang, Q.Y. and Shi, R.H. (1985) Over the Past Century the World Sea Level Changes. Marine Science Bulletin, 4, 1-5.

[16] Chen, X.Q. (1990) Sea-Level Changes from 1922 to 1987 in the Changjiang River Mouth and Its Significance. Acta Geographica Sinica, 45, 387-398.

[17] Department of Geological of the Chinese Academy of Sciences (1994) The Influence and Strategy of Sea Level Rise to Delta Region in China. Science Press, Beijing.

[18] Cazenave, A., Dominh, K., Gennero, M.C. and Ferret, B. (1998) Global Mean Sea Level Changes Observed by Topex-Poseidon Altimetry and ERS-1. Physics and Chemistry of the Earth, 23, 1069-1075.

https://doi.org/10.1016/S0079-1946(98)00146-3

[19] Repert, J.P., Donguy, J.R., Elden, G., et al. (1985) Relations between Sea Level, Thermocline Depth, Heat Content, and Dynamic Height in the Tropical Pacific Ocean. Journal of Geophysical Research, 90, 11719-11725.

https://doi.org/10.1029/JC090iC06p11719

[20] White, W.B. and Tai, C.K. (1995) Inferring Interannual Changes in Global Upper Ocean Heat Storage from TOPEX Altimetry. Journal of Geophysical Research, 100, 24943-24954.

[21] Chambers, D.P., Tapley, B.D. and Stewart, R.H. (1997) Long-Period Ocean Heat Storage Rates and Basin-Scale Heat Fluxes from TOPEX. Journal of Geophysical Research, 102, 10525-10533. https://doi.org/10.1029/96JC03644

[22] Chen, J.L., Shum, C.K., Wilson, C.R., et al. (2000) Seasonal Sea Level Change from TOPEX/Poseidon Observation and Thermal Contribution. Journal of Geodesy, 73, 638-647. https://doi.org/10.1007/s001900050002

[23] Cabanes, C., Cazenave, A. and Le Provost, C. (2001) Sea Level Rise during Past 40 Years Determined from Satellite and in Situ Observations. Science, 294, 840-842. https://doi.org/10.1126/science.1063556

[24] Leuliette, E.W. and Wahr, J.M. (1999) Coupled Pattern Analysis of Sea Surface Temperature and TOPEX/POSEIDON Sea Surface Height. Journal of Physical Oceanography, 29, 599-611. https://doi.org/10.1175/1520-0485(1999)029<0599:CPAOSS >2.0.CO;2

[25] Nerem, R.S. and Mitchum, G.T. (2001) Sea Level Change. In: Fu, L.-L. and Cazenave, A., Eds., Satellite Altimetry and Earth Sciences. A Handbook of Techniques and Applications, Academic Press, Cambridge, 329-347. https://doi.org/10.1016/S0074-6142(01)80153-4

[26] Nerem, R.S. and Mitchum, G.T. (2001) Observations of Sea Level Change from Sa- 
tellite Altimetry. In: Douglas, B.C., Kearney, M.S. and Leatherman, S.P., Eds., Sea Level Rise: History And Consequences, Academic Press, Cambridge, 121-159. https://doi.org/10.1016/S0074-6142(01)80009-7

[27] IPCC (2007) Climate Change 2007: The Physical Science Basis, Summary for Policy makers. Contribution of Working Group I to the Fourth Assessment Report of the Intergovernmental Panel on Climate Change, Intergovernmental Panel on Climate Change.

[28] Nong, G.T., Najjar, R.G., Seidov, D. and Peterson, W.H. (2000) Simulation of Ocean Temperature Change Due to the Opening of Drake Passage. Geophysical Research Letters, 27, 2689-2692. https://doi.org/10.1029/1999GL011072

[29] Najjar, R.G. (2002) Modelling Geographic Impacts on Early Eocene Ocean Temperature. Geophysical Research Letters, 29, 40-1-40-4.

https://doi.org/10.1029/2001GL014438

[30] Cramer, B.S., Toggweiler, J.R., Wright, J.D., Katz, M.E. and Miller, K.G. (2009) Ocean Over-Turning since the Late Cretaceous: Inferences from a New Benthic Foraminiferal Isotope Compilation. Paleoceanography, 24, 1-14.

https://doi.org/10.1029/2008PA001683

[31] Katz, M.E., Cramer, B.S., Toggweiler, J.R., Esmay, G., Liu, C., Miller, K.G., Rosenthal, Y., Wade, B.S. and Wright, J.D. (2011) Impact of Antarctic Circumpolar Current Development on Late Paleogene Ocean Structure. Science, 332, 1076-1079. https://doi.org/10.1126/science.1202122

[32] Gao, S., Zhu, L., Zhang, W., et al. (2020) Western North Pacific Tropical Cyclone Activity in 2018: A Season of Extremes. Scientific Reports, 10, Article No. 5610. https://doi.org/10.1038/s41598-020-62632-5

[33] Pu, Y.X. (1988) The Monthly Average Seasonal Changes in the Sea Level of China Coast. Acta Oceanologica Sinica, 10, 292-302.

[34] Pu, Y.X. and Xu, X.Y. (1986) The Black Tide of the East China Sea (PN Section) during 1972-1983. Acta Oceanologica Sinica, 8, 14-20.

[35] Li, K.P., Fang, X.Y., Liu, L.H., et al. (1993) Response of the Sea Level Changes to Variabilities of the Kuroshio. Marine Science Progress, No. 4, 30-37.

[36] Wang, P.B., Wang, L.Z. and Subrahmanyam, M.V. (2020) Sea Level Variations of Zhejiang Province, China. Open Access Library Journal, 7, e6409.

https://doi.org/10.4236/oalib.1106409

[37] Chen, M. and Li, T. (2018) Why 1986 El Niño and 2005 La Niña Evolved Different from a Typical El Niño and La Niña. Climate Dynamics, 51, 4309-4327. https://doi.org/10.1007/s00382-017-3852-1

[38] Thompson, D.W.J., Wallace, J.M., Kennedy, J.J., et al. (2010) An Abrupt Drop in Northern Hemisphere Sea Surface Temperature around 1970. Nature, 467, 444-447. https://doi.org/10.1038/nature09394

[39] Yu, Y.F. (2004) Advance of Researches on the Variations of Mean-Sea-Level (MSL) in the Coastal Water of China. Periodical of Ocean University of China (Natural Science Edition), 34, 713-719.

[40] Zuo, J.C., Yu, Y.F. and Chen, Z.Y. (1994) The Analysis of Factor along China Coast. Advance in Earth Sciences, 9, 48-53.

[41] The State Oceanic Administration (2012) In 2011 China Sea Level Communique.

[42] Zhang, J.L., Chen, M.C., Chen, M.X., et al. (2009) Characteristics of SST Variation/Change in the Coastal Region of the East China Sea. Proceeding of the Nineteen (2009) International offshore and Polar Engineering Conference, Osaka, 21-26 
June 2009, 483-489.

[43] Cai, R.S., et al. (2010) The Effects of Climate Change on China's Coastal Ecosystem. Ocean Press, Beijing. 